\title{
Field measurements of biogenic volatile organic compounds in the atmosphere using solid-phase microextraction Arrow
}

\author{
Luís Miguel Feijó Barreira $^{1}$, Geoffroy Duporté ${ }^{1}$, Tuukka Rönkkö ${ }^{1}$, Jevgeni Parshintsev ${ }^{1}$, Kari Hartonen ${ }^{1}$, \\ Lydia Hyrsky $^{1}$, Enna Heikkinen ${ }^{1}$, Matti Jussila ${ }^{1}$, Markku Kulmala ${ }^{2}$, and Marja-Liisa Riekkola ${ }^{1}$ \\ ${ }^{1}$ Department of Chemistry, University of Helsinki, P.O. Box 55, 00014 Helsinki, Finland \\ ${ }^{2}$ Department of Physics, University of Helsinki, P.O. Box 64, 00014 Helsinki, Finland
}

Correspondence: Marja-Liisa Riekkola (marja-liisa.riekkola@helsinki.fi)

Received: 9 September 2017 - Discussion started: 17 October 2017

Revised: 13 December 2017 - Accepted: 2 January 2018 - Published: 14 February 2018

\begin{abstract}
Biogenic volatile organic compounds (BVOCs) emitted by terrestrial vegetation participate in a diversity of natural processes. These compounds impact both shortrange processes, such as on plant protection and communication, and long-range processes, for example by participating in aerosol particle formation and growth. The biodiversity of plant species around the Earth, the vast assortment of emitted BVOCs, and their trace atmospheric concentrations contribute to the substantial remaining uncertainties about the effects of these compounds on atmospheric chemistry and physics, and call for the development of novel collection devices that can offer portability with improved selectivity and capacity. In this study, a novel solid-phase microextraction (SPME) Arrow sampling system was used for the static and dynamic collection of BVOCs from a boreal forest, and samples were subsequently analyzed on site by gas chromatography-mass spectrometry (GC-MS). This system offers higher sampling capacity and improved robustness when compared to traditional equilibrium-based SPME techniques, such as SPME fibers. Field measurements were performed in summer 2017 at the Station for Measuring Ecosystem-Atmosphere Relations (SMEAR II) in Hyytiälä, Finland. Complementary laboratory tests were also performed to compare the SPME-based techniques under controlled experimental conditions and to evaluate the effect of temperature and relative humidity on their extraction performance. The most abundant monoterpenes and aldehydes were successfully collected. A significant improvement on sampling capacity was observed with the new SPME Arrow system over SPME fibers, with collected amounts being approximately $2 \times$ higher for monoter-
\end{abstract}

penes and 7-8 $\times$ higher for aldehydes. BVOC species exhibited different affinities for the type of sorbent materials used (polydimethylsiloxane (PDMS)-carbon wide range (WR) vs. PDMS-divinylbenzene (DVB)). Higher extraction efficiencies were obtained with dynamic collection prior to equilibrium regime, but this benefit during the field measurements was small, probably due to the natural agitation provided by the wind. An increase in temperature and relative humidity caused a decrease in the amounts of analytes extracted under controlled experimental conditions, even though the effect was more significant for PDMS-carbon WR than for PDMS-DVB. Overall, results demonstrated the benefits and challenges of using SPME Arrow for the sampling of BVOCs in the atmosphere.

\section{Introduction}

Vegetation covering Earth landmasses release a diversity of biogenic volatile organic compounds (BVOCs), which comprise a large variety of molecules that differ in size, physicochemical properties, and metabolic origin (Laothawornkitkul et al., 2009; Peñuelas and Llusià, 2001; Peñuelas and Staudt, 2010). The terrestrial biosphere functions as one of the key regulators of atmospheric chemistry and is fundamental for sustainability of air quality and climate (Arneth et al., 2010; Bryan and Steiner, 2013). BVOCs participate in many natural processes, including plant metabolism, growth, reproduction, protection, and communication within plant communities and between plants and insects (Laothawornkitkul et al., 2009; Peñuelas and Staudt, 2010). BVOC emissions vary 
considerably in time and space and between species, and are strongly influenced by temperature and light (Kesselmeier and Staudt, 1999; Schollert et al., 2014; Tarvainen et al., 2005). Once in the atmosphere, BVOCs participate in atmospheric reactions, which leads to the formation of numerous secondary products (Atkinson and Arey, 2003). The lifetime of BVOCs varies to a large extent, depending on the compound and oxidants involved (Atkinson and Arey, 2003). The low-volatility secondary products formed in these photooxidation reactions can subsequently result in the formation of secondary organic aerosols (SOA; Jimenez et al., 2009). Aerosols are recognized to affect climate, both directly by reflecting or absorbing solar radiation and indirectly by acting as cloud condensation nuclei (Kulmala et al., 2004). BVOCs are believed to be the largest source of SOA on a global scale (Henze and Seinfeld, 2006).

Monoterpenes are a class of naturally occurring compounds with great importance to atmospheric physics and chemistry. These compounds participate in photochemical reactions that affect ozone and carbon monoxide concentrations, and contribute to secondary organic aerosol formation and growth through their oxidation products (Kavouras et al., 1999; Lerdau et al., 1997). They also have an important biological role, for example as allelopathic and defense compounds against pathogens and herbivores (Kesselmeier and Staudt, 1999). Measurement of monoterpenes is usually performed by online proton transfer reaction-mass spectrometry (PTR-MS; e.g., Aalto et al., 2014; Rantala et al., 2015). This technique offers fast detection of VOCs, high sensitivity, good time resolution, and low detection limits (Graus et al., 2010). However, PTR-MS cannot differentiate compounds with the same molecular mass, and it usually requires the use of long sampling lines that can cause sample alteration. Alternatively, monoterpenes have been successfully sampled on tubes packed with an adsorbent material (such as Tenax TA/Carbopack B) and subsequently desorbed into a thermal desorption-gas chromatograph-mass spectrometer for offline or online analysis (e.g., Haapanala et al., 2012; Hakola et al., 2012; Wong et al., 2013). The main limitation of this method is the requirement of sophisticated instrumentation that is less convenient for field measurements (e.g., thermal desorption unit and cryofocusing). Solid-phase microextraction (SPME) has also been used for the collection of monoterpenes (e.g., Yassaa et al., 2010; Zini et al., 2001). This technique combines sampling and pre-concentration of analytes in a single step and allows for direct thermal desorption into a heated gas chromatograph injection port (Koziel et al., 1999).

Carbonyl compounds also play an important role in the atmosphere due to their involvement in photochemical reactions and contribution to aerosol particle formation and growth (Jang and Kamens, 2001; Kesselmeier and Staudt, 1999). Aldehydes have been sampled in forest air with $\mathrm{C}_{18}$ cartridges coated with a 2,4-dinitrophenylhydrazine (DNPH) derivatization reagent and analyzed by liquid chromatography-mass spectrometry (LC-MS; e.g., Hellén et al., 2004). The main drawbacks of this method are the laborious sample preparation and long sampling times.

The trace amounts of BVOCs in ambient air and their wide variety necessitate the development and application of portable, selective, and robust sampling and preconcentration techniques. In our previous research, SPME fibers and needle trap microextraction (NTME) syringes combined with portable GC-MS have been successfully used for the sampling and analysis of BVOCs in a boreal forest (Barreira et al., 2015, 2016). These methods have several advantages, such as full portability, low infrastructure/resource demands, high pre-concentration, no sample preparation, and fast on-site analysis. However, the low mixing ratios of some of these compounds in forest atmosphere call for additional improvements in pre-concentration. In this study, SPME Arrow was tested for the collection of BVOCs from boreal forest ambient air. This novel SPME-based system consists of a steel rod coated with a larger amount of sorbent material than the traditional SPME fibers, offering increased capacity but maintaining the compatibility for direct thermal desorption and analysis in a conventional GC-MS due to its shape and dimensions (Helin et al., 2015). The coated rod can be withdrawn in a steel needle, which makes the device more robust. Samples were collected simultaneously by SPME fibers for comparison purposes. The effect of meteorological parameters at the sampling place on the SPME sampling was tentatively evaluated. The inherent characteristics of SPMEbased sampling techniques and coating materials used in this work (polydimethylsiloxane/divinylbenzene (PDMS-DVB) and PDMS-carbon wide range (WR)) were studied in the laboratory before the field campaign. Static and dynamic SPME Arrow collection modes were also compared.

\section{Material and methods}

\subsection{Chemicals and materials}

$\alpha$-Pinene (98\%), $\Delta^{3}$-carene ( $\left.\geq 98.5 \%\right)$, limonene $(\geq 99 \%)$, octanal (99\%), nonanal (98\%), and decanal ( $\geq 98 \%$ ) from Sigma-Aldrich (St. Louis, USA) were used as standards. Stock solutions were prepared in dichloromethane $(99.99 \%$, Fisher Scientific, Loughborough, UK) and subsequently diluted with the same solvent to obtain needed concentrations for the calibration of instrument response. For laboratory studies, diffusion vials were prepared by adding small amounts of standards to headspace vials $(20 \mathrm{~mL})$ and inserting a piece of deactivated-fused-silica retention gap $(1.5 \mathrm{~m} \times 0.53 \mathrm{~mm}$ inner diameter (ID), Agilent Technologies, Palo Alto, USA) through the septa, to allow a constant diffusion of the compounds from the vials. These vials were inserted into a homemade permeation oven, and the calibration gas flow was diluted with nitrogen and subsequently transferred to an additional chamber from where samples were 
collected. The diffusion rates were measured by weighting the vials on five different days and determining the amount of analyte losses per time. The obtained diffusion rates were $0.252 \mathrm{mg} \mathrm{h}^{-1}$ for $\alpha$-pinene, $0.129 \mathrm{mg} \mathrm{h}^{-1}$ for $\Delta^{3}$-carene, and $0.070 \mathrm{mg} \mathrm{h}^{-1}$ for octanal, which correspond to concentrations of $149 \mathrm{ppbv}$ for $\alpha$-pinene, $76 \mathrm{ppbv}$ for $\Delta^{3}$-carene, and $44 \mathrm{ppbv}$ for octanal. The decanal diffusion rate was not possible to determine, probably due to slow evaporation from the diffusion vial. SPME fibers coated with PDMS-DVB (65 $\mu \mathrm{m}$, Supelco, Bellafonte, PA, USA) and PDMS-carbon WR (95 $\mu$ m, CTC Analytics AG, Zwingen, Switzerland), and SPME Arrows coated with the same PDMS-carbon WR $(120 \mu \mathrm{m})$ and PDMS-DVB $(120 \mu \mathrm{m})$ types of sorbents (CTC Analytics AG, Zwingen, Switzerland) were used for analyte collection. The SPME fibers had a sorbent length of $10 \mathrm{~mm}$, while SPME Arrows had a sorbent length of $20 \mathrm{~mm}$. The diameter of Arrow needle was $1.1 \mathrm{~mm}$. All SPME fibers and SPME Arrows were pre-conditioned according to the manufacturer's instructions.

\subsection{Measurement site}

BVOC sampling was performed at the SMEAR II station (Station For Measuring Ecosystem-Atmosphere Relations; $61^{\prime} 50.845^{\prime \prime} \mathrm{N}, 24^{\prime} 17.686^{\prime \prime} \mathrm{E}$; $179 \mathrm{~m}$ above sea level) in Hyytiälä, southern Finland (Hari and Kulmala, 2005). The station is situated in an approximately 55-year-old and relatively homogeneous Scots pine stand, with a canopy height of about $21 \mathrm{~m}$ and average tree density of 1170 steams ha $^{-1}$. The forest around the station is dominated by conifers (mainly Scots pine and Norway spruce). Tampere is the largest neighboring region, with approximately half a million inhabitants, and is located $60 \mathrm{~km}$ southwest from the SMEAR II station. The sampling site was situated about $1 \mathrm{~m}$ from a $127 \mathrm{~m}$ high mast for atmospheric and flux measurements mounted $2 \mathrm{~m}$ above the average forest floor.

\subsection{Sampling and analysis}

Ambient air samples were collected and analyzed on site from 11 to 15 August 2017. For comparison purposes, one PDMS-DVB SPME fiber, two PDMS-DVB SPME Arrows and one PDMS-carbon WR SPME Arrow were used. Samples were collected in static mode for $45 \mathrm{~min}$, to sample detectable amounts of target analytes with all SPME systems and to reduce the significance of errors associated with the time lag between sampling and injection. Additionally, a homemade dynamic sampling system for SPME Arrow was used for comparison with static SPME collection (Fig. S1 in the Supplement). This device was adapted and modified from the sampling system developed in previous research for SPME fibers (Barreira et al., 2015). Samples were measured using a conventional GC-MS, consisting of an Agilent $6890 \mathrm{~N}$ gas chromatograph equipped with an Agilent 5973 mass selective detector (Agilent Tech- nologies, Palo Alto, USA). The analytical column was a HP-5MS $(30 \mathrm{~m} \times 0.25 \mathrm{~mm} \times 0.25 \mu \mathrm{m}$, Agilent Technologies, Palo Alto, CA, USA). The initial oven temperature was $70^{\circ} \mathrm{C}(1 \mathrm{~min})$, and it was increased to $250^{\circ} \mathrm{C}(1 \mathrm{~min})$ at $20^{\circ} \mathrm{C} \mathrm{min}-1$. The total run time was $11 \mathrm{~min}$. Helium (99.996\%, AGA, Espoo, Finland) was used as a carrier gas in a constant-flow mode $\left(1.5 \mathrm{~mL} \mathrm{~min}{ }^{-1}\right)$. SPME Arrow and fibers were desorbed in splitless mode $(2 \mathrm{~min})$ with a $2.0 \mathrm{~mm}$ ID split/splitless inlet liner. Desorption temperature was $270^{\circ} \mathrm{C}$ for all the SPME devices. A standard inlet septum was used for SPME Arrow, while a 23-gauge Merlin Microseal and a Merlin nut (Merlin Instrument Company, Half Moon Bay, USA) were used in the injection port for conventional SPME fibers. The temperature of the GC-MS transfer line was $250^{\circ} \mathrm{C}$, and the ion source and quadrupole temperatures were kept at 230 and $150^{\circ} \mathrm{C}$, respectively. Electron ionization $(70 \mathrm{eV})$ was used. The scan mass range was from 30 to $400 \mathrm{amu}$. The mass spectra and retention times of each analyte were obtained with standard solutions and used for identification of studied compounds in the collected samples. For semi-quantitation, extracted ion chromatograms with base ions were used $\left(\mathrm{m} / z, 93\right.$ for $\alpha$-pinene, $\Delta^{3}$-carene, and limonene; $m / z 43$ for octanal and decanal; and $m / z 57$ for nonanal).

The same method was employed for the laboratory tests, although the initial oven temperature was $50^{\circ} \mathrm{C}(1 \mathrm{~min})$ and the final temperature $250^{\circ} \mathrm{C}(1 \mathrm{~min})$ at $20^{\circ} \mathrm{C} \mathrm{min}-1$. For the laboratory determination of analytes extraction time profiles and to compare the extraction efficiencies of the different SPME-based sampling techniques, an Agilent 5975 C mass selective detector (Agilent Technologies, Palo Alto, USA) was also used, while all other laboratory tests were performed with the same GC-MS used for the field measurements. Samples were collected over $10 \mathrm{~min}$, except for when studying the effects of temperature and relative humidity (RH) on the collection of BVOCs, when a 20 min sampling time was chosen.

\section{Results}

In this work, a novel SPME Arrow system was optimized and tested in the laboratory to study its applicability for the field measurement of BVOCs in forest atmosphere. The characterization of SPME-based techniques, including kinetics of extraction, comparison of techniques and adsorbent extraction performances, and influence of temperature and relative humidity on the extracted amounts are described in the first sections. The measurements performed in the field and comparison with atmospheric temperature, relative humidity, ozone (measured at $4.2 \mathrm{~m}$ height), precipitation, photosynthetically active radiation (PAR), and particle number concentration (PNC; available at http://avaa.tdata.fi/web/smart and provided by Junninen et al., 2009) are then further discussed. 

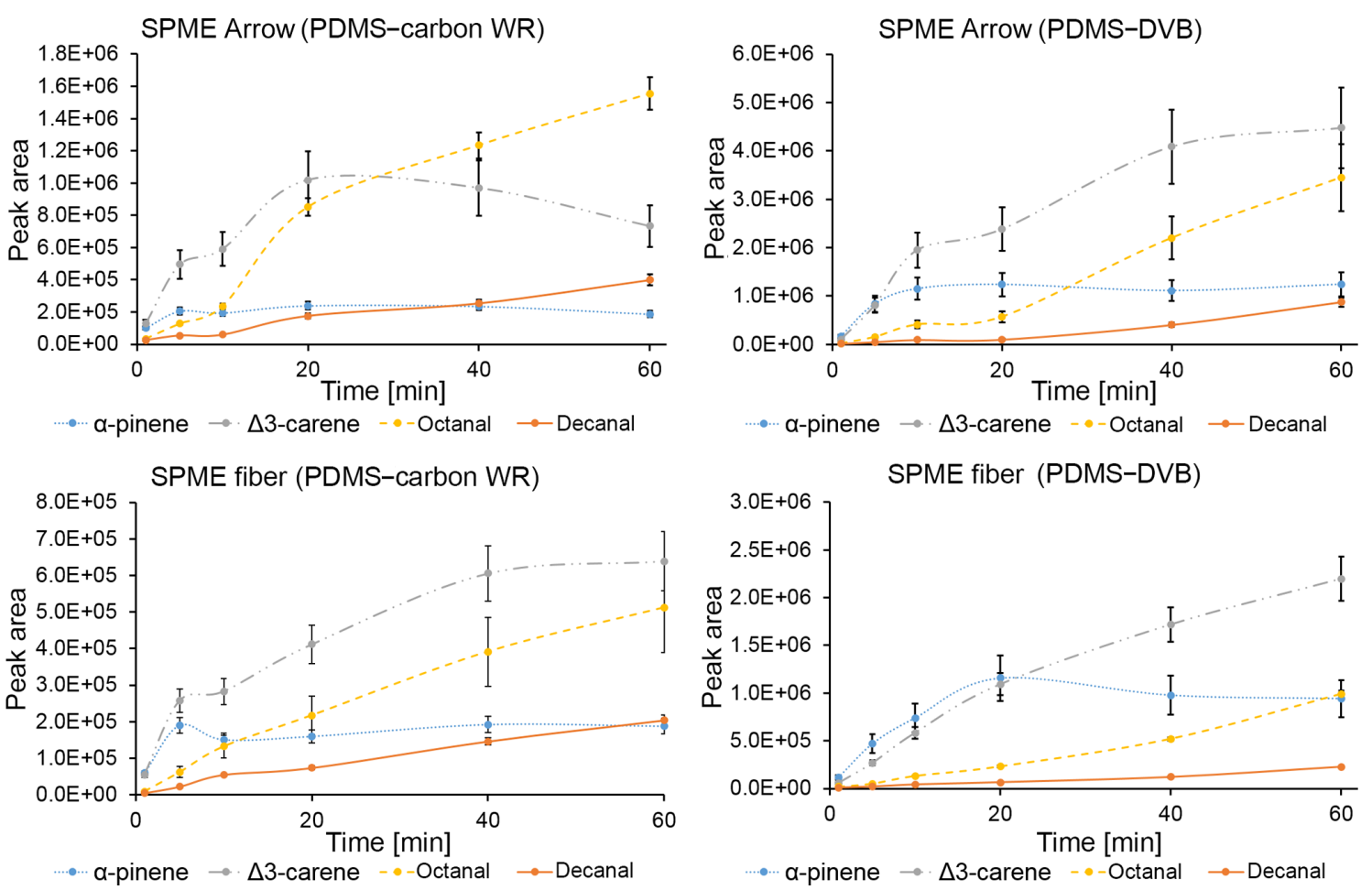

Figure 1. Extraction time profiles obtained for the studied analytes using SPME fiber and SPME Arrow coated with PDMS-carbon WR and PDMS-DVB.

\subsection{Characterization of SPME-based sampling techniques}

\subsubsection{Extraction time profile}

The extraction time profiles for $\alpha$-pinene, $\Delta^{3}$-carene, octanal, and decanal were obtained in this study, to evaluate the occurrence of equilibrium and/or competitive adsorption during an experimental sampling time of $1 \mathrm{~h}$ at laboratory ambient temperature. These compounds have been reported as some of the most abundant monoterpenes and aldehydes at the sampling site (e.g., Barreira et al., 2016). For an estimation of standard deviations during kinetic studies, three repetitions were performed at $10 \mathrm{~min}$, corresponding to the minimum sampling time used during all other experiments and consequently to the higher expected variation. $\alpha$-Pinene reached equilibrium after $10 \mathrm{~min}$ of extraction when a SPME Arrow coated with PDMS-DVB was used, and after $20 \mathrm{~min}$ with a SPME fiber coated with the same material (Fig. 1). For PDMS-carbon WR, $\alpha$-pinene equilibrium was reached already after $5 \mathrm{~min}$ of sampling for both SPME-based techniques. $\Delta^{3}$-Carene did not reach equilibrium when using PDMS-DVB for $1 \mathrm{~h}$, while with PDMS-carbon WR equilibrium was reached after $20 \mathrm{~min}$ for SPME Arrow and $40 \mathrm{~min}$ for SPME fiber. These results show that kinetics of extraction are faster with PDMS-carbon WR than with PDMS-DVB. The extraction time profiles for the aliphatic aldehydes stud- ied showed that these compounds did not reach equilibrium after 60 min of sampling.

In the obtained extraction time profiles, analyte amounts did not decrease with time when using a SPME fiber and SPME Arrow coated with PDMS-DVB and a SPME fiber coated with PDMS-carbon WR. This evidence suggests that interanalyte displacement due to competitive adsorption was not observed during the period of sampling, which is particularly interesting for PDMS-DVB since the uniformity of its micropores has been reported to potentially result in the displacement of analytes with less affinity by the ones with highest affinity (Pawliszyn, 2011). However, some displacement was observed for $\Delta^{3}$-carene when using SPME Arrow coated with PDMS-carbon WR.

The extraction time profile for a dynamic sampling with SPME Arrow coated with PDMS-carbon WR was also obtained (Fig. 2). As expected, equilibrium was reached much faster than in static mode. This fact is clearly observed for octanal, which reached equilibrium in $40 \mathrm{~min}$, while in static mode it was not achieved during the experimental time. However, displacement effects were also observed for $\Delta^{3}$-carene. 


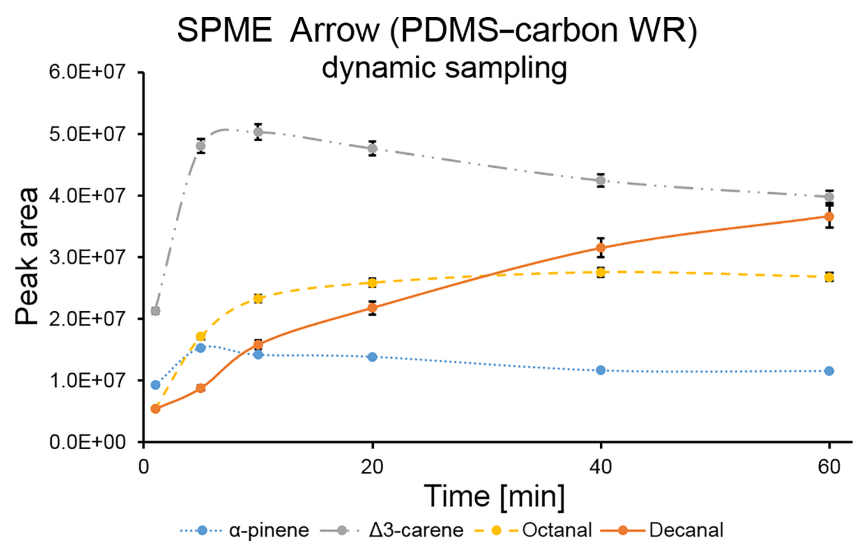

Figure 2. Extraction time profiles obtained for the studied analytes using dynamic sampling by SPME Arrow coated with PDMScarbon WR.

\subsubsection{Extraction efficiencies of different SPME-based techniques}

A comparison between SPME Arrow and SPME fiber extraction efficiencies was performed under the laboratory conditions described in the previous section. Three repetitions were performed with each SPME system. As shown in Fig. 3, extraction efficiency of SPME Arrow was approximately $2 \times$ higher than for SPME fiber for PDMS-DVB and $3 \times$ higher for PDMS-carbon WR after 10 min of sampling, even though this improvement was slightly different depending on the analytes. Compound-specific extraction efficiencies were distinct for PDMS-DVB and PDMS-carbon WR. PDMS-DVB had the best affinity towards monoterpenes, while there was no statistically significant difference between materials for aldehydes. Both materials adsorbed more $\Delta^{3}$-carene than $\alpha$ pinene. At first glance, this selective adsorption seems to be greater for PDMS-carbon WR than for PDMS-DVB. However, the equilibrium was not reached for all the studied compounds, and a longer sampling time, such as the one used in the field measurements ( $45 \mathrm{~min}$ ), will then impact the relative amounts of analytes collected with both materials (Fig. 1). Extraction efficiencies of sampling modes were also compared. Static and dynamic collections were performed for 10 min. As observed in Fig. S2, $\alpha$-pinene amounts were similar with both static and dynamic sampling. This result is expected since when equilibrium is reached the analyte collection is no longer influenced by the sampling mode used. However, kinetics of extraction are much faster with dynamic sampling, which results in a higher amount of analyte extracted in less time. On the other hand, the collected amounts of $\Delta^{3}$-carene and studied aldehydes were higher in dynamic mode under pre-equilibrium conditions.

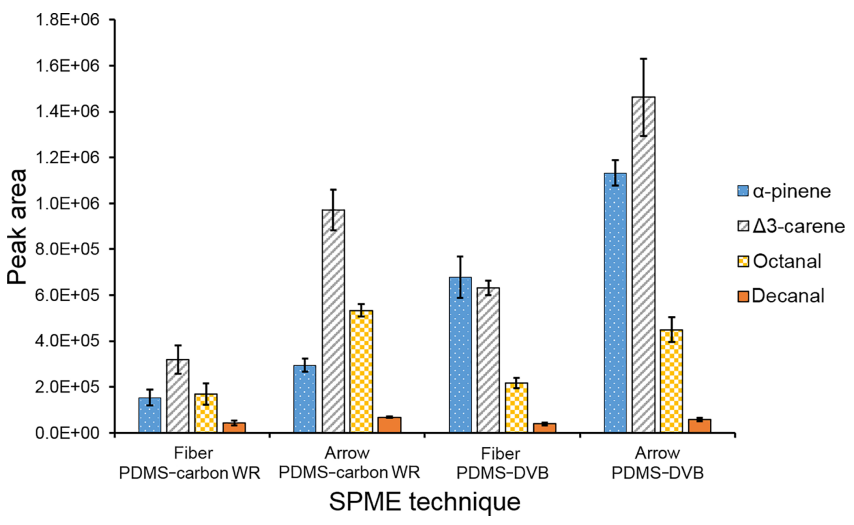

Figure 3. Comparison of the extraction efficiencies obtained with SPME Arrow and SPME fiber coated with PDMS-carbon WR and PDMS-DVB.

\subsubsection{Effect of temperature and relative humidity on the extraction}

The effects of temperature and relative humidity on the SPME Arrow extraction efficiencies for the studied analytes were evaluated under controlled conditions. The total sampling time was $20 \mathrm{~min}$, which was considered enough to note any effect of these parameters on the extracted amounts. Three replicates were performed for each temperature and relative humidity studied. An increase in temperature is recognized to affect SPME collection by decreasing the distribution constant. The change in distribution constant with temperature is also dependent on the molar change in enthalpy of the analyte when it moves from the gas phase to the fiber sorbent (Pawliszyn, 2011). According to our results, the temperature effect changes significantly depending on the coating material and the analyte. As observed in Fig. 4, the effect of temperature was more significant for $\alpha$-pinene, especially when using a PDMS-carbon WR material. On the other hand, temperature had a smaller effect on the extraction of $\Delta^{3}$-carene, which is more pronounced when using a PDMS-carbon WR adsorbent. Extraction efficiencies of octanal and decanal were not influenced by temperature. Similar results were obtained for SPME fibers coated with the same sorbents (Fig. S3). These results are expected due to the differences in molar change in enthalpy of the analytes when they move from the air to the sorbent, which cause distinct changes in the partition coefficient at different temperatures. An underestimation of the measured amounts of a compound with higher volatility or an overestimation relative to the most volatile compounds are then expected when quantifying monoterpenes under field conditions where temperature changes can be significant. The effect of temperature on the amounts of analytes collected by SPME must consequently be assessed or avoided during quantitative field measurements. 

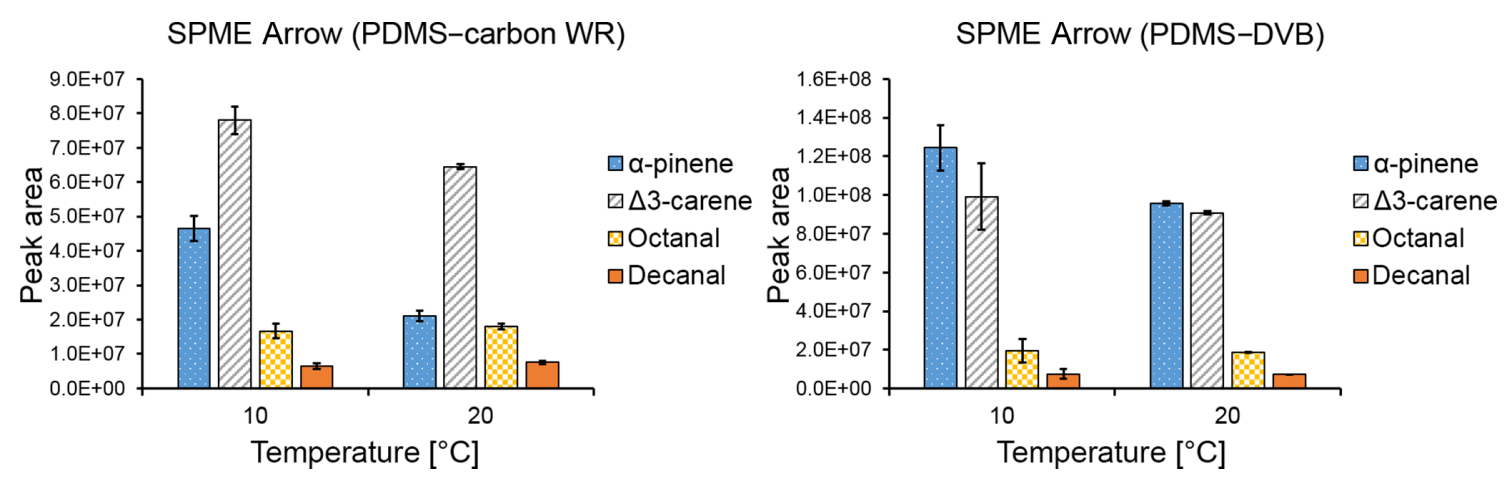

Figure 4. Effect of temperature $\left({ }^{\circ} \mathrm{C}\right)$ on the extraction efficiencies obtained with SPME Arrow using PDMS-carbon WR and PDMS-DVB sorbents.
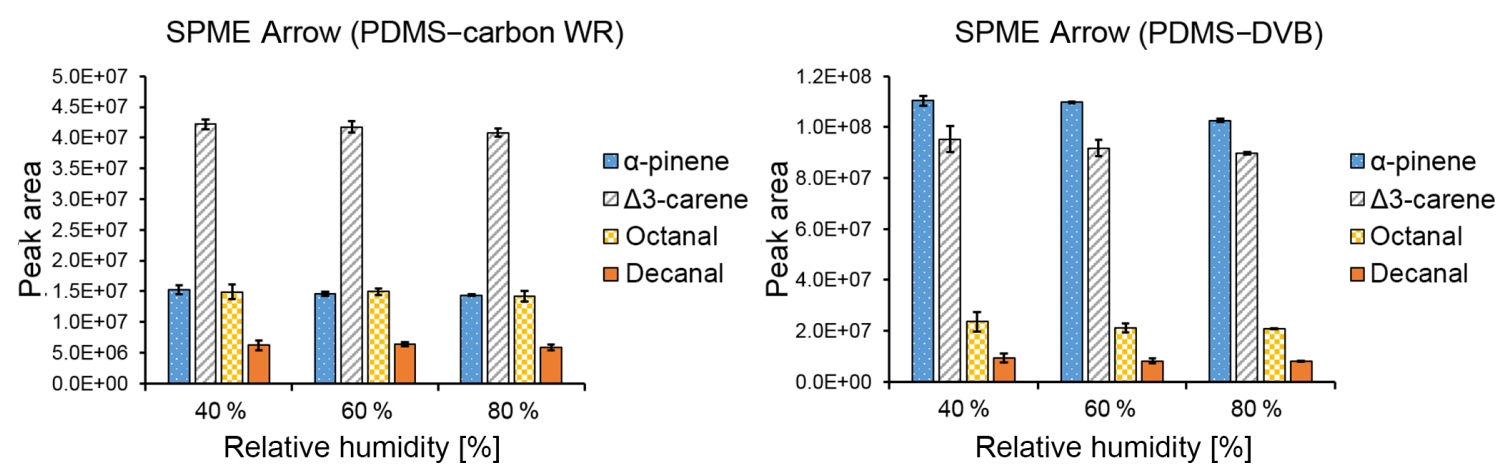

Figure 5. Effect of relative humidity (\%) on the extraction efficiencies obtained with SPME Arrow using with PDMS-carbon WR and PDMS-DVB sorbents.

The effect of relative humidity on the extraction efficiency of SPME fibers has been observed previously (e.g., Namieśnik et al., 2003). However, in our study, this effect was expected to be small due to the high hydrophobicity of SPME coating materials used. Indeed, relative humidity had a small influence on the extraction performances of both SPME Arrows (Fig. 5) and SPME fibers (Fig. S4). The small effect of relative humidity when using hydrophobic materials has also been observed previously, where the extraction of benzene, toluene, $p$-xylene, and ethylbenzene with a PDMS-DVB-coated SPME fiber at different humidity showed a maximum reduction of the mass adsorbed by approximately $21 \%$ after $1 \mathrm{~h}$ of sampling (Koziel et al., 2000). A small effect of relative humidity on the SPME extraction when using hydrophobic coatings was also shown in another study, where two carbon-based SPME coatings were used for the sampling of 1,1,1-trichloroethane and carbon tetrachloride (Chai and Pawliszyn, 1995). In the publication referred to, relative humidity reduced the amounts of extracted analytes at ambient temperature by less than $10 \%$ at up to $75 \%$ RH. Even though the effect of relative humidity was negligible in our study, this parameter might greatly influence the SPME collection when using other sorbents or when sampling other analytes.

\subsection{Calibration of instrument response}

The calibration of instrument response was performed for the field measurement of monoterpenes ( $\alpha$-pinene, $\Delta^{3}$-carene, and limonene) and aldehydes (octanal, nonanal, and decanal), to estimate the mass adsorbed on the coating materials of the different SPME-based systems (Table S1 in the Supplement). Liquid standard solutions at different concentrations were used for this purpose. A linear four-point calibration curve ( 0.1 to $10 \mathrm{ng}$ ) was obtained for monoterpenes, while a linear five-point calibration curve ( 0.1 to $50 \mathrm{ng}$ ) was obtained for aldehydes. Three repetitions were done for each concentration level. The intermediate reproducibility $\left(R_{w}\right)$, expressed as relative standard deviation (RSD), was from 0.2 to $19.5 \%$ for monoterpenes and from 2.0 to $18.7 \%$ for aldehydes, with higher RSD for lower concentration levels. A good linearity and sufficient correlation coefficients were observed for the mass ranges used. The limits of detection (LOD), which are also given in Table S1, varied from 17.7 to $28 \mathrm{pg}$ for monoterpenes, while the LOD values obtained for aldehydes were from 61.1 to $155.2 \mathrm{pg}$. 


\subsection{Atmospheric levels of organic volatile compounds identified in air samples}

In this study, three monoterpenes were identified during field measurements, namely $\alpha$-pinene, $\Delta^{3}$-carene, and limonene (Fig. S5 and Table S2). The extracted amounts of BVOCs were on the order of a few nanograms, which is in line with our preliminary measurements done in the previous year using an SPME Arrow coated with polydimethylsiloxane (PDMS)/carbon WR and the same method as in this work (Fig. S6). The atmospheric levels of these BVOCs have been intensively determined at the SMEAR II boreal forest station and are known to be dominated by $\alpha$-pinene and $\Delta^{3}$-carene (Rinne et al., 2000; Yassaa et al., 2012). Similar results have also been found in our previous research by using a SPME fiber (PDMS-DVB) combined with portable GC-MS (Barreira et al., 2015). Limonene has also been found in previous research, but at relative amounts that were considerably smaller than the most abundant monoterpenes (e.g., Barreira et al., 2015; Rinne et al., 2000; Yassaa et al., 2012). The dominance of $\alpha$-pinene and $\Delta^{3}$-carene was observed in this study when considering the peak areas obtained by conventional GC-MS (Fig. S7). However, when the calibration of analytes response was performed with standard solutions (but not the calibration of SPME collection), $\Delta^{3}$-carene, and limonene levels increased relatively to $\alpha$-pinene (Fig. 6a). This fact is particularly significant for limonene, which even overcomes the levels of $\alpha$-pinene when SPME Arrow is used as a sampling device. Furthermore, PDMS-carbon WR enhanced the differences when compared to PDMS-DVB. These results show that the materials used in this study are particularly selective for these compounds, especially for limonene. The preferential adsorption of both materials for $\Delta^{3}$-carene compared to $\alpha$-pinene was also demonstrated in the laboratory studies described earlier (Sect. 3.1.2). Furthermore, $\Delta^{3}$ carene amounts are enhanced by the temperature and relative humidity effects on $\alpha$-pinene extraction described in Sect. 3.1.3, this effect being more marked for PDMS-carbon WR.

Aliphatic aldehydes - particularly octanal, nonanal, and decanal - were identified in this study (Fig. S5 and Table S2). These aldehydes have also been reported in another research study performed in a boreal forest (Hellén et al., 2004). The most abundant aldehydes measured during the sampling campaign were nonanal and decanal, while octanal amounts were relatively small and only measurable when a SPME Arrow system was used (Fig. 6b). These aldehydes were more adsorbed with PDMS-DVB than with PDMS-carbon WR, which was not observed in the laboratory experiments. The reason for this result might be related to the different times of collection and kinetics of adsorption, since equilibrium was not reached in those experiments. During field measurements, the presence of wind speed or air bulk movement significantly affects the mass transfer process from bulk air to the sorbent (Pawliszyn, 2011), which can reveal differences in the adsorption of these compounds.

A comparison between SPME fiber and SPME Arrow was also performed, to evaluate quantitatively the enrichment provided by the SPME Arrows. Only PDMS-DVB was used for comparison in this study, since it was the less sensitive material to changes in temperature and relative humidity during the laboratory experiments. The monoterpenes were highly enriched when using SPME Arrow instead of the conventional SPME fiber (Fig. 7a). The amounts of monoterpenes measured when using SPME Arrow were approximately $2 \times$ more than with the SPME fiber of the same material, which resembles the results obtained in the laboratory experiments. The enhancement was also slightly different depending on the analytes. However, compound-specific extraction efficiencies were observed. The ratio between $\Delta^{3}$ carene and $\alpha$-pinene was approximately 1.4 when using a SPME fiber, but it went up to 1.8 with SPME Arrow. This fact was found as well in the laboratory experiments, where a ratio of 0.9 was obtained for these compounds with the SPME fiber, while a ratio of 1.3 was observed for SPME Arrow. The difference is less significant between limonene and $\alpha$-pinene, with a ratio of 1.0 for the SPME fiber and 1.1 for the SPME Arrow, and between $\Delta^{3}$-carene and limonene, with ratios of 1.5 and 1.6 respectively.

The SPME Arrow system also improved the collection of aliphatic aldehydes when compared to SPME fibers (Fig. 7b). Interestingly, the improvement effect of SPME Arrow was much higher than the one verified in the laboratory studies, with amounts increasing 7 to $8 \times$ as compared to the SPME fiber. However, the sampling time for the laboratory experiments was shorter, and equilibrium has not been reached for aldehydes. Furthermore, the wind influences the mass transfer process from air to the sorbent during the field experiments. Both of these facts impact the amounts adsorbed in SPME and can cause the observed differences in the enrichment with SPME Arrow.

Static and dynamic collection modes were compared for the SPME Arrow coated with PDMS-DVB. The extraction amounts were slightly higher when dynamic sampling was used. This result was observed for all monoterpenes (Fig. 8a) and aldehydes (Fig. 8b) identified and measured during the sampling campaign. However, the differences were relatively small, suggesting the proximity to or the attainment of the equilibrium state where an increase in the time of extraction does not result in higher amounts of analyte extracted on the SPME materials. A likely reason for this evidence is related to the fact that during field sampling wind improves the mass transfer from air to the sorbent in a similar way to the sampling devices used for dynamic extraction. In fact, VOC mass loading on the sorbent increases with an increase in wind velocity from 0 to $5 \mathrm{~cm} \mathrm{~s}^{-1}$ (Pawliszyn, 2011), and for that reason dynamic sampling is recommended to eliminate this effect. The main drawback when collection is performed in dynamic mode is that compounds with lower affinity for the 

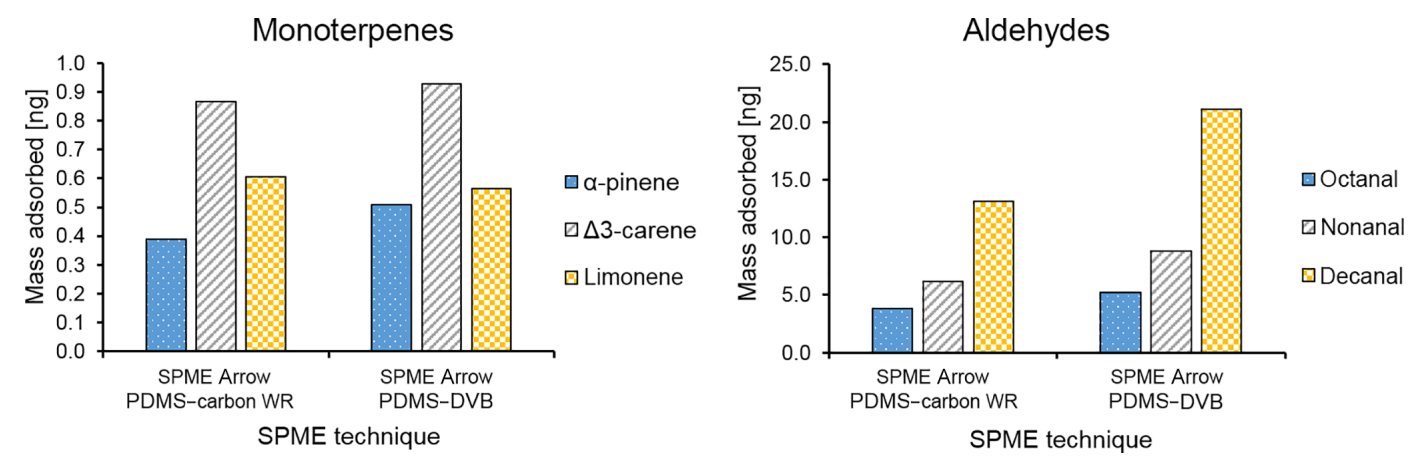

Figure 6. Comparison between the average mass of identified monoterpenes ( $\alpha$-pinene, $\Delta^{3}$-carene, and limonene) and aldehydes (octanal, nonanal, and decanal) collected with different SPME Arrow sorbents (PDMS-DVB and PDMS-carbon WR) from ambient air and measured by GC-MS.
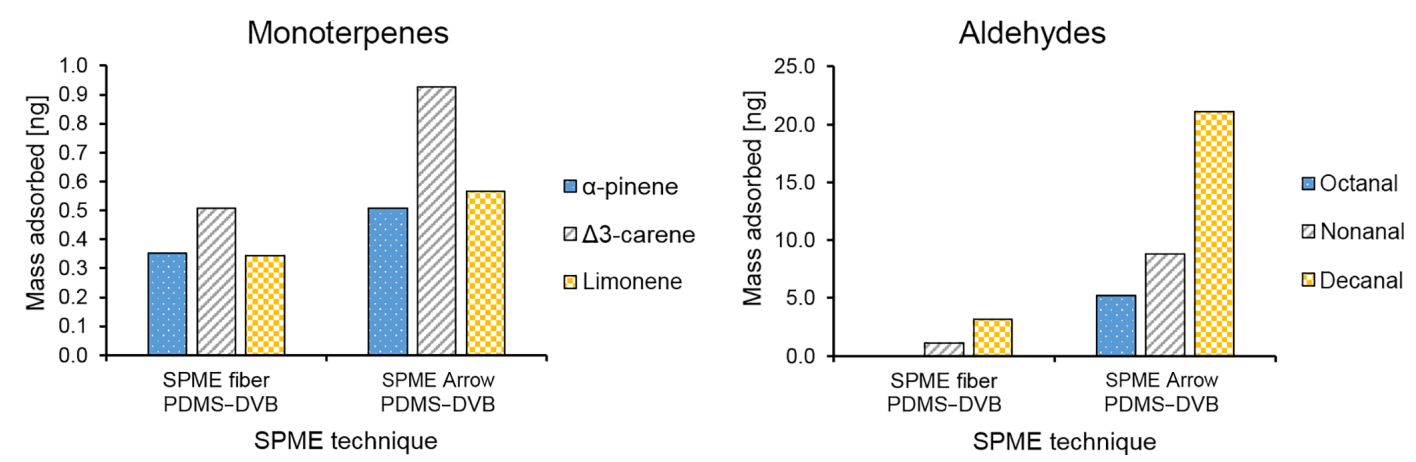

Figure 7. Comparison between the average mass of identified monoterpenes ( $\alpha$-pinene, $\Delta^{3}$-carene, and limonene) and aldehydes (octanal, nonanal, and decanal) collected with different PDMS-DVB SPME devices (fiber and Arrow) from ambient air and measured by GC-MS.

coating are more susceptible to displacement effects (e.g., Tuduri et al., 2002). A decrease in extraction time can partially prevent these effects, even though it might also cause a decrease in sensitivity that can compromise the possibility of measuring some of the BVOCs present at trace levels in the atmosphere.

\subsection{Effect of meteorological parameters on the atmospheric levels of VOCs}

The effects of meteorological parameters (Table S3) on the measured atmospheric levels of monoterpenes (Fig. 9) and aldehydes (Fig. 10) were also tentatively evaluated in this study, since some of these parameters can influence not only the VOC emissions/atmospheric mixing ratios but also the adsorption on the SPME sorbent materials. The ratios between the amounts of monoterpenes and aldehydes sampled with PDMS-carbon WR and PDMS-DVB were also compared with the mentioned parameters, in order to understand if meteorological conditions affect the sampling with these materials differently (Fig. S8).

Temperature has two opposing effects in field measurements performed at boreal forest sites. Increased temperature enhances VOC emissions from Scots pine (Tarvainen et al., 2005). In addition, it reduces the distribution constant of the analytes because adsorption is an exothermic process (de Fatima Alpendurada, 2000). During the sampling campaign, temperature remained almost constant, limiting the comparison between this parameter and the measured amounts of monoterpenes. The effect of temperature was then expected to be small when compared to other parameters, which was verified in our results. However, longer data sets encompassing periods of greater temperature variation are needed to perform this evaluation.

RH and precipitation also have two opposing effects, since monoterpene emission rates not only increase at high humidity levels and during and after precipitation (Llusià and Peñuelas, 1999; Schade et al., 1999) but also cause a small decrease in the SPME extraction capacity (Sect. 3.1.3). Oppositely to temperature, relative humidity varied considerably during the sampling campaign, which allowed the effect of this parameter to be studied in our results. An increase in monoterpene amounts was observed during a precipitation event when relative humidity was high, showing that the decreasing effect of these parameters on the sorbent collection is less significant than their increasing effect on VOC emissions. A correlation was not found when considering the ratio between the amounts of monoterpenes sampled with PDMS- 

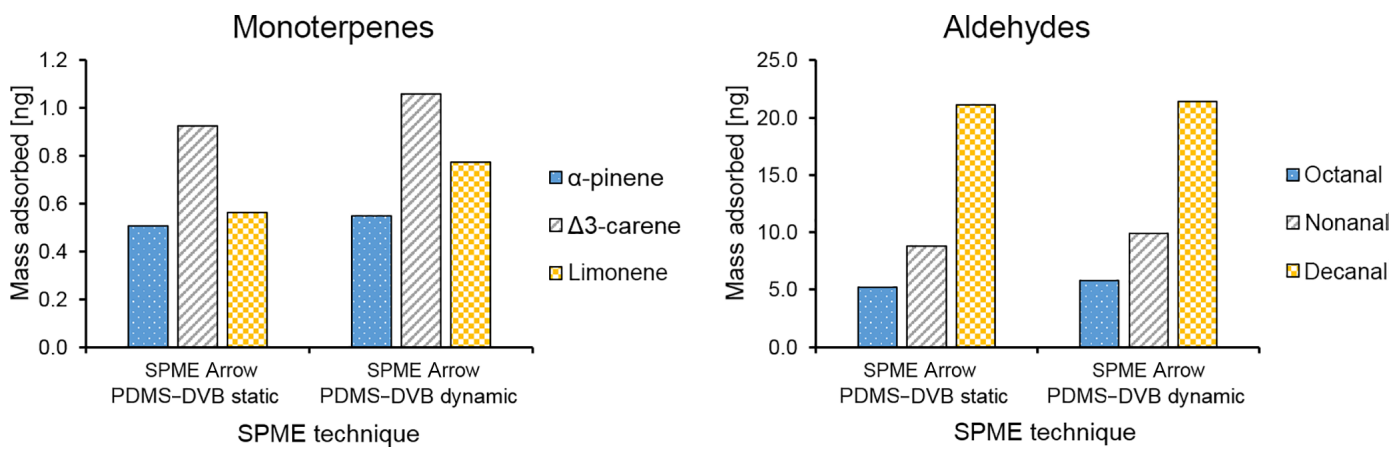

Figure 8. Comparison between the average mass of identified monoterpenes ( $\alpha$-pinene, $\Delta^{3}$-carene, and limonene) and aldehydes (octanal, nonanal, and decanal) collected with different sampling modes (static and dynamic) by SPME Arrow (PDMS-DVB) from ambient air and measured by GC-MS.
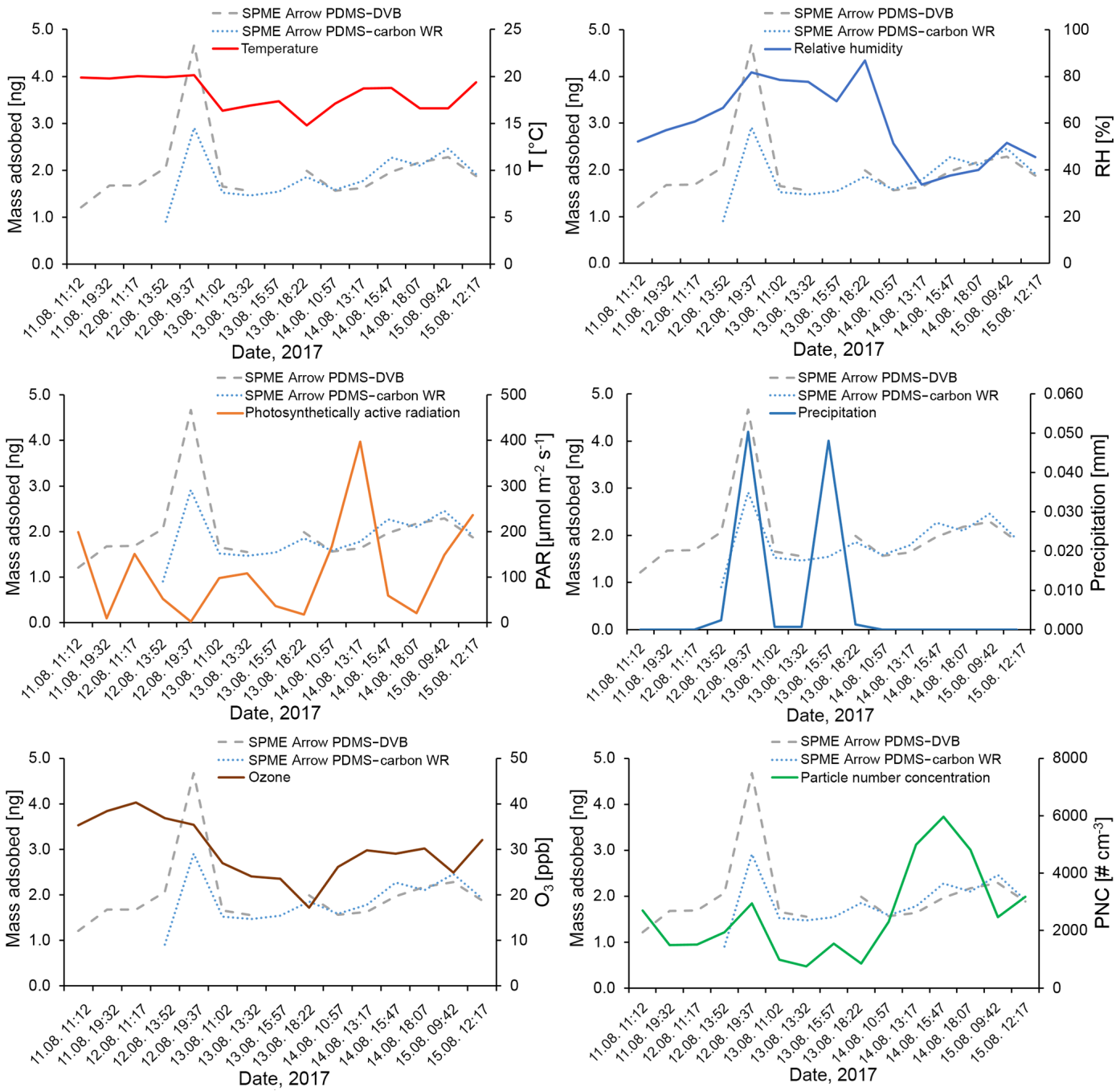

Figure 9. Effect of temperature $\left({ }^{\circ} \mathrm{C}\right)$, relative humidity $(\%)$, photosynthetically active radiation $\left(\mu m o l \mathrm{~m}^{-2} \mathrm{~s}^{-1}\right)$, precipitation $(\mathrm{mm})$, ozone (ppb), and particle number concentration $\left(\# \mathrm{~cm}^{-3}\right.$ ) on the mass of monoterpenes adsorbed on the SPME Arrows used in this study (PDMSDVB and PDMS-carbon WR) and measured by GC-MS. 

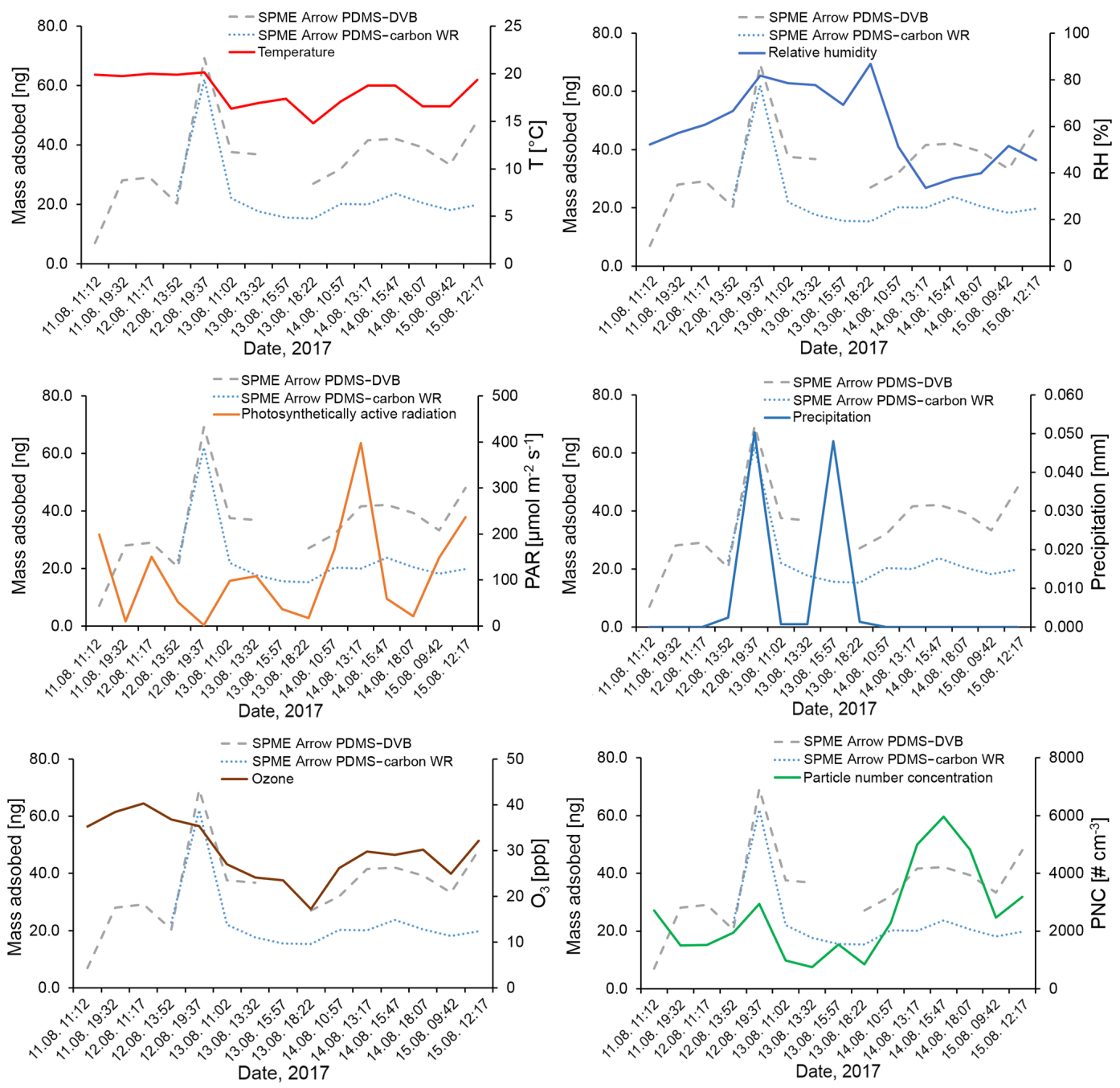

Figure 10. Effect of temperature $\left({ }^{\circ} \mathrm{C}\right)$, relative humidity $(\%)$, photosynthetically active radiation $\left(\mu \mathrm{mol} \mathrm{m}{ }^{-2} \mathrm{~s}^{-1}\right)$, precipitation $(\mathrm{mm})$, ozone $(\mathrm{ppb})$, and particle number concentration $\left(\# \mathrm{~cm}^{-3}\right)$ on the mass of aldehydes adsorbed on the SPME Arrows used in this study (PDMS-DVB and PDMS-carbon WR) and measured by GC-MS.

carbon WR and PDMS-DVB, which is consistent with the small humidity dependence observed for the sampling with these materials under controlled laboratory conditions.

Due to the constancy of temperature during the sampling campaign, ozone and PAR were also expected to significantly affect the measured amounts of monoterpenes. Indeed, some anti-correlation was found between the measured monoterpenes and these parameters. This result is likely to reflect the increased photooxidation during periods of the day when PAR is high, since the effects of temperature and/or light on monoterpene emissions have been described previously (Aalto et al., 2014). Nonetheless, on-fiber oxidation might occur during SPME collection. For that reason, the effect of oxidants must be assessed further by performing complementary laboratory experiments under controlled conditions. Ozone and PAR did not distinctively affect the ad- sorption on the two different materials used in this study. PNC also seemed to increase with the amounts of monoterpenes present in the ambient air. This result is expected, since monoterpene oxidation in the atmosphere and consequent formation of low-volatility compounds have been recognized to contribute to aerosol particle formation (Laaksonen et al., 2008). However, other factors can also contribute to the increase in PNC, such as long-range transport.

With reference to aldehydes, the studied parameters seemed not to negatively influence the SPME collection. A similar trend between aldehyde amounts and temperature was observed during the most of the sampling period, showing that temperature did not affect the SPME sampling and suggesting the existence of a temperature dependence on aldehyde emissions. However, as referred to previously, temperature remained almost constant during the sampling 
campaign, and additional studies under controlled conditions are required to confirm this evidence. Relative humidity and precipitation also coincided with a burst in aldehyde atmospheric amounts, excluding a negative effect of this parameter on the SPME sampling, but seemed to anti-correlate with these parameters when aldehyde amounts were low. This observation could be a consequence of the solubility of these compounds in water at low concentrations, but additional studies are also required to confirm this hypothesis. A correlation was not found between PAR and aldehydes. However, contrary to monoterpenes, some correlation with ozone was observed, which was expected since increased emissions have been reported in another study when vegetation was exposed to ozone (Wildt et al., 2003). On-fiber oxidation studies are also still required for aldehydes. The effect of aldehyde amounts on PNC was not very clear, which might be a consequence of the lower atmospheric reactivity of these compounds. No correlation was observed between atmospheric parameters and the ratio between the amounts collected on PDMS-carbon WR and PDMS-DVB, which agrees with the non-dependences on temperature and relative humidity verified in laboratory studies.

Even though the effects of atmospheric parameters on the SPME sampling were preliminarily evaluated with our method under atmospherically relevant conditions, longer data sets and quantitative data are needed to accurately estimate the correlation of these parameters with BVOC mixing ratios.

\section{Conclusions}

A novel SPME Arrow system was tested in this study for the collection of BVOCs in a boreal forest (SMEAR II, Hyytiälä, Finland). Conventional SPME fibers were used for comparison. Samples were successfully collected with both SPME-based sampling systems and were analyzed by conventional GC-MS. Neither additional sampling line nor sample pre-treatment was needed, reducing analysis time, sample contamination, and potential losses. The most abundant monoterpenes and aldehydes were measured. PDMS-carbon WR had higher affinity towards $\Delta^{3}$-carene and limonene than PDMS-DVB, while PDMS-DVB enhanced the extraction of $\alpha$-pinene. Nonanal and decanal were the most abundant aliphatic aldehydes. The extraction efficiency of SPME Arrow was about 2 times higher than that of SPME fiber, with an exception for aldehydes during the field campaign, where a seven- to eightfold enhancement was observed. Dynamic sampling demonstrated higher extraction efficiencies than static mode prior to equilibrium, but the improvement during field measurements was small due to the effect of wind speed on the extraction and/or to the fact that extraction was near equilibrium. Meteorological parameters influenced the amounts of studied BVOCs in the atmosphere but did not seem to significantly influence the SPME sampling.
However, laboratory tests showed that temperature and relative humidity decrease the extracted amounts of BVOCs, especially the ones with higher volatility and when PDMScarbon WR is used. Overall, results demonstrated the potential of SPME Arrow for the in situ measurement of BVOCs in the atmosphere and the challenges that need to be solved for using these devices for quantitative purposes. More studies under controlled conditions are needed to understand the influence of co-adsorbed species and oxidants on the SPME sampling and to develop a proper calibration method for quantitative field measurements. Longer data sets are also required to study in more detail the effects of atmospheric parameters on the SPME sampling under atmospherically relevant conditions.

Data availability. All data used in the publication are given in the Supplement to this article and can be used by third parties.

Supplement. The supplement related to this article is available online at: https://doi.org/10.5194/amt-11-881-2018-supplement.

Competing interests. The authors declare that they have no conflict of interest.

Acknowledgements. Financial support was provided by the Academy of Finland Centre of Excellence program (grant no. 307331). CTC Analytics AG (Zwingen, Switzerland) and BGB Analytik AG (Zurich, Switzerland) are thanked for their cooperation. The staff of the Laboratory of Analytical Chemistry and Smear II station are thanked for the collaboration.

Edited by: Yoshiteru Iinuma

Reviewed by: two anonymous referees

\section{References}

Aalto, J., Kolari, P., Hari, P., Kerminen, V.-M., Schiestl-Aalto, P., Aaltonen, H., Levula, J., Siivola, E., Kulmala, M., and Bäck, $\mathrm{J} .:$ New foliage growth is a significant, unaccounted source for volatiles in boreal evergreen forests, Biogeosciences, 11, 13311344, https://doi.org/10.5194/bg-11-1331-2014, 2014

Arneth, A., Harrison, S. P., Zaehle, S., Tsigaridis, K., Menon, S., Bartlein, P. J., Feichter, J., Korhola, A., Kulmala, M., and O'Donnell, D.: Terrestrial biogeochemical feedbacks in the climate system, Nat. Geosci., 3, 525-532, https://doi.org/10.1038/ngeo905, 2010.

Atkinson, R. and Arey, J.: Gas-phase tropospheric chemistry of biogenic volatile organic compounds: a review, Atmos. Environ., 37, 197-219, https://doi.org/10.1016/S1352-2310(03)00391-1, 2003.

Barreira, L. M. F., Parshintsev, J., Kärkkäinen, N., Hartonen, K., Jussila, M., Kajos, M., Kulmala, M., and Riekkola, M.-L.: Field 
measurements of biogenic volatile organic compounds in the atmosphere by dynamic solid-phase microextraction and portable gas chromatography-mass spectrometry, Atmos. Environ., 115, 214-222, https://doi.org/10.1016/j.atmosenv.2015.05.064, 2015.

Barreira, L. M. F., Xue, Y., Duporté, G., Parshintsev, J., Hartonen, K., Jussila, M., Kulmala, M., and Riekkola, M.L.: Potential of needle trap microextraction-portable gas chromatography-mass spectrometry for measurement of atmospheric volatile compounds, Atmos. Meas. Tech., 9, 3661-3671, https://doi.org/10.5194/amt-9-3661-2016, 2016.

Bryan, A. M. and Steiner, A. L.: Canopy controls on the forest-atmosphere exchange of biogenic ozone and aerosol precursors, Mich. J. Sustain., 1, 31-49, https://doi.org/10.3998/mjs.12333712.0001.005, 2013.

Chai, M. and Pawliszyn, J.: Analysis of environmental air samples by solid-phase microextraction and gas chromatography/ion trap mass spectrometry, Environ. Sci. Technol., 29, 693-701, https://doi.org/10.1021/es00003a017, 1995.

de Fatima Alpendurada, M.: Solid-phase microextraction: a promising technique for sample preparation in environmental analysis, J. Chromatogr. A, 889, 3-14, https://doi.org/10.1016/S00219673(00)00453-2, 2000.

Graus, M., Müller, M., and Hansel, A.: High resolution PTR-TOF: quantification and formula confirmation of VOC in real time, J. Am. Soc. Mass Spectr., 21, 1037-1044, https://doi.org/10.1016/j.jasms.2010.02.006, 2010.

Haapanala, S., Hakola, H., Hellén, H., Vestenius, M., Levula, J., and Rinne, J.: Is forest management a significant source of monoterpenes into the boreal atmosphere?, Biogeosciences, 9, 12911300, https://doi.org/10.5194/bg-9-1291-2012, 2012.

Hakola, H., Hellén, H., Hemmilä, M., Rinne, J., and Kulmala, M.: In situ measurements of volatile organic compounds in a boreal forest, Atmos. Chem. Phys., 12, 11665-11678, https://doi.org/10.5194/acp-12-11665-2012, 2012.

Hari, P. and Kulmala, M.: Station for measuring ecosystematmosphere relations, Boreal Environ. Res., 10, 315-322, 2005.

Helin, A., Rönkkö, T., Parshintsev, J., Hartonen, K., Schilling, B., Läubli, T., and Riekkola, M.-L.: Solid phase microextraction Arrow for the sampling of volatile amines in wastewater and atmosphere, J. Chromatogr. A, 1426, 56-63, https://doi.org/10.1016/j.chroma.2015.11.061, 2015.

Hellén, H., Hakola, H., Reissell, A., and Ruuskanen, T. M.: Carbonyl compounds in boreal coniferous forest air in Hyytiälä, Southern Finland, Atmos. Chem. Phys., 4, 1771-1780, https://doi.org/10.5194/acp-4-1771-2004, 2004.

Henze, D. K. and Seinfeld, J. H.: Global secondary organic aerosol from isoprene oxidation, Geophys. Res. Lett., 33, 1-4, https://doi.org/10.1029/2006GL025976, 2006.

Jang, M. and Kamens, R. M.: Atmospheric secondary aerosol formation by heterogeneous reactions of aldehydes in the presence of a sulfuric acid aerosol catalyst, Environ. Sci. Technol., 35, 4758-4766, https://doi.org/10.1021/es010790s, 2001.

Jimenez, J., Canagaratna, M., Donahue, N., Prevot, A., Zhang, Q., Kroll, J. H., DeCarlo, P. F., Allan, J. D., Coe, H., Ng, N., Aiken, A., Docherty, K., Ulbrich, I., Grieshop, A., Robinson, A., Duplissy, J., Smith, J., Wilson, K., Lanz, V., Hueglin, C., Sun, Y., Tian, J., Laaksonen, A., Raatikainen, T., Rautiainen, J., Vaattovaara, P., Ehn, M., Kulmala, M., Tomlinson, J., Collins, D., Cubison, M., Dunlea, E., Huffman, J., Onasch, T., Alfarra, M.,
Williams, P., Bower, K., Kondo, Y., Schneider, J., Drewnick, F., Borrmann, S., Weimer, S., Demerjian, K., Salcedo, D., Cottrell, L., Griffin, R., Takami, A., Miyoshi, T., Hatakeyama, S., Shimono, A., Sun, J., Zhang, Y., Dzepina, K., Kimmel, J., Sueper, D., Jayne, J., Herndon, S., Trimborn, A., Williams, L., Wood, E., Middlebrook, A., Kolb, C., Baltensperger, U., and Worsnop, D.: Evolution of organic aerosols in the atmosphere, Science, 326, 1525-1529, https://doi.org/10.1126/science.1180353, 2009.

Junninen, H., Lauri, A., Keronen, P., AaIto, P., Hiltunen, V., Hari, P., and Kulmala, M.: Smart-SMEAR: on-line data exploration and visualization tool tor SMEAR stations, Boreal Environ. Res., 14, 447-457, 2009.

Kavouras, I. G., Mihalopoulos, N., and Stephanou, E.: Formation and gas/particle partitioning of monoterpenes photooxidation products over forests, Geophys. Res. Lett., 26, 55-58, https://doi.org/10.1029/1998GL900251, 1999.

Kesselmeier, J. and Staudt, M.: Biogenic volatile organic compounds (VOC): an overview on emission, physiology and ecology, J. Atmos. Chem., 33, 23-88, https://doi.org/10.1023/A:1006127516791, 1999.

Koziel, J., Jia, M., Khaled, A., Noah, J., and Pawliszyn, J.: Field air analysis with SPME device, Anal. Chim. Acta, 400, 153-162, https://doi.org/10.1016/S0003-2670(99)00614-5, 1999.

Koziel, J., Jia, M., and Pawliszyn, J.: Air sampling with porous solid-phase microextraction fibers, Anal. Chem., 72, 5178-5186, https://doi.org/10.1021/ac0005181, 2000.

Kulmala, M., Suni, T., Lehtinen, K. E. J., Dal Maso, M., Boy, M., Reissell, A., Rannik, Ü., Aalto, P., Keronen, P., Hakola, H., Bäck, J., Hoffmann, T., Vesala, T., and Hari, P.: A new feedback mechanism linking forests, aerosols, and climate, Atmos. Chem. Phys., 4, 557-562, https://doi.org/10.5194/acp-4-557-2004, 2004.

Laaksonen, A., Kulmala, M., O’Dowd, C. D., Joutsensaari, J., Vaattovaara, P., Mikkonen, S., Lehtinen, K. E. J., Sogacheva, L., Dal Maso, M., Aalto, P., Petäjä, T., Sogachev, A., Yoon, Y. J., Lihavainen, H., Nilsson, D., Facchini, M. C., Cavalli, F., Fuzzi, S., Hoffmann, T., Arnold, F., Hanke, M., Sellegri, K., Umann, B., Junkermann, W., Coe, H., Allan, J. D., Alfarra, M. R., Worsnop, D. R., Riekkola, M.-L., Hyötyläinen, T., and Viisanen, Y.: The role of VOC oxidation products in continental new particle formation, Atmos. Chem. Phys., 8, 2657-2665, https://doi.org/10.5194/acp-8-2657-2008, 2008.

Laothawornkitkul, J., Taylor, J. E., Paul, N. D., and Hewitt, C. N.: Biogenic volatile organic compounds in the Earth system, New Phytol., 183, 27-51, https://doi.org/10.1111/j.14698137.2009.02859.x, 2009.

Lerdau, M., Litvak, M., Palmer, P., and Monson, R.: Controls over monoterpene emissions from boreal forest conifers, Tree Physiol., 17, 563-569, https://doi.org/10.1093/treephys/17.8-9.563, 1997.

Llusià, J. and Peñuelas, J.: Pinus halepensis and Quercus ilex terpene emission as affected by temperature and humidity, Biol. Plantarum, 42, 317-320, https://doi.org/10.1023/A:1002185324152, 1999.

Namieśnik, J., Jastrzebska, A., and Zygmunt, B.: Determination of volatile aliphatic amines in air by solidphase microextraction coupled with gas chromatography with flame ionization detection, J. Chromatogr. A, 1016, 1-9, https://doi.org/10.1016/S0021-9673(03)01296-2, 2003. 
Pawliszyn, J.: Handbook of solid phase microextraction, Elsevier, 497 pp., 2011.

Peñuelas, J. and Llusià, J.: The complexity of factors driving volatile organic compound emissions by plants, Biol. Plantarum, 44, 481-487, https://doi.org/10.1023/A:1013797129428, 2001.

Peñuelas, J. and Staudt, M.: BVOCs and global change, Trends Plant Sci., 15, 133-144, https://doi.org/10.1016/j.tplants.2009.12.005, 2010.

Rantala, P., Aalto, J., Taipale, R., Ruuskanen, T. M., and Rinne, J.: Annual cycle of volatile organic compound exchange between a boreal pine forest and the atmosphere, Biogeosciences, 12, 5753-5770, https://doi.org/10.5194/bg-12-5753-2015, 2015.

Rinne, J., Hakola, H., Laurila, T., and Rannik, Ü.: Canopy scale monoterpene emissions of Pinus sylvestris dominated forests, Atmos. Environ., 34, 1099-1107, https://doi.org/10.1016/S13522310(99)00335-0, 2000.

Schade, G. W., Goldstein, A. H., and Lamanna, M. S.: Are monoterpene emissions influenced by humidity?, Geophys. Res. Lett., 26, 2187-2190, https://doi.org/10.1029/1999GL900444, 1999.

Schollert, M., Burchard, S., Faubert, P., Michelsen, A., and Rinnan, R.: Biogenic volatile organic compound emissions in four vegetation types in high arctic Greenland, Polar Biol., 37, 237-249, https://doi.org/10.1007/s00300-013-1427-0, 2014.

Tarvainen, V., Hakola, H., Hellén, H., Bäck, J., Hari, P., and Kulmala, M.: Temperature and light dependence of the VOC emissions of Scots pine, Atmos. Chem. Phys., 5, 989-998, https://doi.org/10.5194/acp-5-989-2005, 2005.
Tuduri, L., Desauziers, V., and Fanlo, J. L.: Dynamic versus static sampling for the quantitative analysis of volatile organic compounds in air with polydimethylsiloxane-Carboxen solidphase microextraction fibers, J. Chromatogr. A, 963, 49-56, https://doi.org/10.1016/S0021-9673(02)00222-4, 2002.

Wildt, J., Kobel, K., Schuh-Thomas, G., and Heiden, A. C.: Emissions of oxygenated volatile organic compounds from plants Part II: emissions of saturated aldehydes, J. Atmos. Chem., 45, 173196, https://doi.org/10.1023/A:1024030821349, 2003.

Wong, G. K., Ng, S. J., and Webster, R. D.: Quantitative analysis of atmospheric volatile organic pollutants by thermal desorption gas chromatography mass spectrometry, Anal. Methods-UK, 5, 219-230, https://doi.org/10.1039/C2AY25982F, 2013.

Yassaa, N., Custer, T., Song, W., Pech, F., Kesselmeier, J., and Williams, J.: Quantitative and enantioselective analysis of monoterpenes from plant chambers and in ambient air using SPME, Atmos. Meas. Tech., 3, 1615-1627, https://doi.org/10.5194/amt-3-1615-2010, 2010.

Yassaa, N., Song, W., Lelieveld, J., Vanhatalo, A., Bäck, J., and Williams, J.: Diel cycles of isoprenoids in the emissions of Norway spruce, four Scots pine chemotypes, and in Boreal forest ambient air during HUMPPA-COPEC-2010, Atmos. Chem. Phys., 12, 7215-7229, https://doi.org/10.5194/acp-127215-2012, 2012.

Zini, C. A., Augusto, F., Christensen, E., Smith, B. P., Caramão, E. B., and Pawliszyn, J.: Monitoring biogenic volatile compounds emitted by Eucalyptus citriodora using SPME, Anal. Chem., 73, 4729-4735, https://doi.org/10.1021/ac0103219, 2001. 